\title{
Gas Chromatography-Mass Spectrometry (GC-MS) Analysis of Indole Alkaloids Isolated from Catharanthus roseus (L.) G. Don Cultivated Conventionally and Derived from In vitro Cultures
}

\author{
Aneta WESOŁOWSKA ${ }^{1 *}$, Monika GRZESZCZUK², Janusz WILAS², \\ Danuta KULPA ${ }^{3}$ \\ ${ }^{1}$ West Pomeranian University of Technology Szczecin, Faculty of Chemical Engineering, Institute of Chemistry and Environmental Protection, Aleja Piastów 42, 71-065 Szczecin, \\ Poland;Aneta.Wesolowska@zut.edu.pl('correspondingauthor) \\ ${ }^{2}$ West Pomeranian University of Technology Szzzecin, Faculty of Environmental Management and Agriculture, Department of Horticulture, Stowackiego 17, 71-434 Szczecin \\ Poland:Monika_Grzeszzuk@zut.edu.pl;Janusz.Wilas@zut.edu.pl \\ ${ }^{3}$ West Pomeranian University of Technology Szczecin, Faculty of Environmental Management and Agriculture, Department of Plant Genetics, Breeding and Biotechnology, \\ Stowackiego 17,71-434Szczecin,Poland;DanutaKulpa@zut.edu.pl
}

\begin{abstract}
Catharanthus roseus (periwinkle) is a medicinal plant commonly known for its wide biological activity. In many countries different parts of this plant are used for the treatment of diabetes, hypertension and for menstrual regulation. Due to the ability of production of alkaloids, which can be applied in cancer therapy, is still extensively investigated. Two, the most valuable alkaloids (vincristine and vinblastine) are present in C. roseus in very low concentrations. Micropropagation is promising technique used to enhance the level of important secondary metabolites. The main objective of present study was alkaloids extraction from plants cultivated conventionally and derived from in vitro cultures. In this order the aerial parts of periwinkle were extracted with $96 \%$ ethanol at room temperature (method I) and heated with $96 \%$ ethanol at $55^{\circ} \mathrm{C}$ for 90 minutes (method II). The obtained mixtures of different indole alkaloids were analyzed by gas chromatography - mass spectrometry (GC-MS). Analysis revealed the presence of 15 alkaloids, among which vindoline, vindorosine, isovindolinine and ajmalicine were the most abundant. The obtained results indicated that the propagation method had a significant effect on the percentage content of alkaloids in C. roseus herb. Plants derived from in vitro cultures were richer in vindorosine and vindoline, while conventionally cultivated - in tetrahydroalstonine and ajmalicine. Moreover, in case of isovindolinine, vindolinine and ajmalicine, extraction at $55^{\circ} \mathrm{C}$ was more effective, while for pericyclivine - maceration at room temperature. Interestingly, the pericyclivine was not detected in the mixture of alkaloids obtained from periwinkle herb by the extraction at $55^{\circ} \mathrm{C}$.
\end{abstract}

Keywords: bioactivity, extraction method, Madagascar periwinkle, Vinca alkaloids, tissue cultures

\section{Introduction}

Catharanthus roseus (L.) G. Don, known as Vinca rosea or Madagascar periwinkle, can be found as an ornamental subshrub in gardens throughout the world (Larbie and Abboah-Offei, 2014). In addition to its pharmaceutical value, periwinkle has long been cultivated as a herbal medicine. It has been used for centuries to treat diabetes, high blood pressure, fever, malaria and chest complaints (Aslam et al., 2010; Gajalakshmi et al., 2013; Kumari and Gupta, 2013). In India, juice from the periwinkle flowers has been used to treat skin problems, dermatitis, eczema and acne, while juice from the leaves has been applied for wasp stings (El-Sayed and Cordell, 1981). The antibacterial, antifungal, antiviral and antioxidant properties of this herb have also been well documented (Carev and Patterson, 1970; Garg, 2010).

C. roseus is also a rich source of monomeric and dimeric indole alkaloids, which possess antihypertensive and anticancer activities (Kulkarni et al., 1999; Mishra et al., 2001). Anticancer drugs, vincristine and vinblastine, are produced in vivo by the condensation of vindoline and catharanthine, two monomeric precursors (Noble, 1990; Laflamme et al., 2001). These two dimeric alkaloids may be used as single agents or in combination therapy for the treatment of acute leukemia and Hodgkin's disease as well as for a wide variety of neoplasms including breast, bladder and lung cancers (Noble, 1990; Ramirez et al., 1997; Tabakovic et al., 1997). Other alkaloids, such as ajmalicine and serpentine are used as antihypertensive and anti- 
neuro-inflammatory agents, while vindoline, tetrahydroalstonine, catharanthine and vindolinine exhibit hypoglycemic activity (Svoboda, 1969; Marles and Farnsworth, 1995; Almagro et al., 2015).

The alkaloid content varies considerably in the individual parts of $C$. roseus. In the leaves ranges from 0.32 to $1.16 \%$, in the stems from 0.074 to $0.48 \%$, in the flowers from 0.005 to $0.84 \%$, while in roots - between 0.14 and $1.34 \%$ (Joy et al., 1998).

Periwinkle is still intensively studied because of its valuable properties. Researchers are trying to increase the synthesis of alkaloids through the technique of tissue cultures. Also analytical methods for the rapid identification and quantitative extraction of alkaloids are continuously improved.

The aim of this research was to compare the alkaloid composition of Catharanthus roseus cultivated conventionally and derived from in vitro cultures using GC-MS method. Moreover, two different extraction methods were applied in order to show the influence of temperature on identified alkaloids.

\section{Materials and Methods}

\section{Plantmaterial}

The research material consisted of herb (leafy flowered stems) of periwinkle (Catharanthus roseus (L.) G. Don 'Mediterranean Lilac' (Thompson \& Morgan, England).

The field experiment was carried out at the experimental station which belongs to the Department of Horticulture of the West Pomeranian University of Technology Szczecin (NorthWestern Poland). The experiment was established in randomized blocks with four replications. The experimental plot area was 2.75 $\mathrm{m}^{2}$ (40 plants per plot). The field was prepared according to agrotechnique proper for periwinkle cultivation (Thomas et al., 2012). Mineral fertilization, in the form of NPK, was applied during the field preparation, in amounts: 20:30:30 kg.ha ${ }^{-1}$, according to Khode et al. (2000).

There were two methods of plant propagation compared in this study: generative (conventional method of cultivation from seedlings) and in vitro propagation.

In the conventional method, the seedlings of periwinkle were produced in the greenhouse. Seeds were sown in trays with peat moss, on $26^{\text {th }}$ February. The trays were kept in the greenhouse at the temperature $22 \pm 2{ }^{\circ} \mathrm{C}$ and relative humidity $60 \pm 5 \%$. Seedlings were transferred to multiplates containing peat moss on $24^{\text {th }}$ April and then transplanted into the open field on $28^{\text {th }}$ June, at a density of $25 \times 20 \mathrm{~cm}$.

In the in vitro propagation seeds of Catharanthus roseus were immersed in $70 \%$ ethanol for 30 seconds followed by surface disinfection in $7.5 \% \mathrm{NaClO}$ for 15 minutes. Seeds were transferred onto initiation media containing macro- and microelements according to MS medium (Murashige and Skoog, 1962). Seedlings, initiated for growth, were proliferated three times on the MS media with $2.0 \mathrm{mg} \cdot \mathrm{dm}^{-3} \mathrm{KIN}$ (kinetin) and $1.0 \mathrm{mg} \cdot \mathrm{dm}-$ ${ }^{3}$ IBA (indole-3-butyric acid). Propagated shoots of length $1 \mathrm{~cm}$ from previous stage were transferred onto rooting media $-1 / 2 \mathrm{MS}$ (half-strength concentrations of the major and minor salts of the MS medium) with $0.2 \mathrm{mg} \cdot \mathrm{dm}^{-3} \mathrm{NAA}$ ( $\alpha$-naphtahleneacetic acid). At all stages of experiments the media were supplemented with 8 g.dm ${ }^{-3}$ agar and $30 \mathrm{~g} \cdot \mathrm{dm}^{-3}$ sucrose and $100 \mathrm{mg} \cdot \mathrm{dm}^{-3}$ inositol and their $\mathrm{pH}$ was adjusted to 5.7 using the solutions: $0.1 \mathrm{M} \mathrm{NaOH}$ and $\mathrm{HCl}$. After adding growth regulators, the media were autoclaved for 20 minutes at the temperature $121^{\circ} \mathrm{C}$. Every stage lasted 6 weeks. The cultures were placed in a growth chamber at the temperature $24 \pm 1^{\circ} \mathrm{C}$ and then for month in a greenhouse at the temperature $22 \pm 2^{\circ} \mathrm{C}$.

After the acclimatization, plants were transplanted into the open field on $28^{\text {th }}$ June, at a density of $25 \times 20 \mathrm{~cm}$.

During the growing season the crop management was carried out. It included mainly irrigation, weeding and soil cultivation.

The plant harvest was done at full-bloom stage, on $29^{\text {th }}$ July. For the laboratory analyses $100 \mathrm{~g}$ samples (periwinkle herb), from each experimental plot $(4 \times 100 \mathrm{~g})$, were taken. The obtained plant material was dried in a through-flow laboratory dryer set at $35^{\circ} \mathrm{C}$.

\section{Chemicals}

All solvents used in the experiments were of analytical grade. Dichloromethane, ethyl acetate, hexane, 96\% ethanol, hydrochloric acid (35-35\%), sulphuric acid (95\%) and ammonia solution (25\%) were purchased from Chempur (Piekary Ślackie, Poland) and used as received. Alkaloids standards, vindoline (purity 98\%), ajmalicine (purity 98\%) and tetrahydroalstonine (Aldrich $^{\mathrm{CPR}}$ ) were purchased from Sigma-Aldrich, Poznań, Poland. The n-alkane $\left(\mathrm{C}_{7}-\mathrm{C}_{40}\right)$ standard solution $\left(1000 \mu \mathrm{g} \mathrm{mL} \mathrm{m}^{-1}\right.$ each component in hexane) was purchased from Supelco, Poznań, Poland.

\section{Extraction of monoterpene indole alkaloids}

Monoterpene indole alkaloids were extracted according to the methodology described by Misra et al. (2009) (method I) and Miranda-Ham et al. (2007) (method II), with small modifications.

Method I: dried, milled herb of periwinkle (2.5 g) was extracted with $96 \%$ ethanol $(25 \mathrm{~mL})$ through maceration (overnight) and filtered. The residue was again extracted with ethanol and pooled ethanolic extract was evaporated to the dryness. Green, dried residue was redissolved in ethanol $(25 \mathrm{~mL})$, diluted with distilled water $(25 \mathrm{~mL})$ and acidified with $3 \%$ hydrochloric acid to $\mathrm{pH} 1$.

This mixture was extracted three times with hexane $(3 \times 25$ $\mathrm{mL})$. Hexane fraction was discarded. The remaining aqueous layer was cooled to $10^{\circ} \mathrm{C}$, basified with $25 \%$ ammonia solution to $\mathrm{pH} 10$ and extracted with dichloromethane $(3 \times 25 \mathrm{~mL})$. The combined dichloromethane extract was washed with $25 \mathrm{~mL}$ of brine, dried over anhydrous sodium sulphate and evaporated to dryness to give $0.04 \mathrm{~g} ; 1.6 \%$ (conventional cultivation) and 0.05 g; $2 \%$ (in vitro propagation), brownish-yellow alkaloid mixture, respectively.

Method II: $2.5 \mathrm{~g}$ of dried, milled herb of periwinkle in 100 $\mathrm{mL}$ round bottomed flask containing $25 \mathrm{~mL}$ of $96 \%$ ethanol was heated at $55^{\circ} \mathrm{C}$ for 90 minutes using magnetic stirrer. After filtration, the ethanolic extract was evaporated to the dryness and the residue was dissolved in $104 \mathrm{~mL} \mathrm{2.5 \%} \mathrm{sulphuric} \mathrm{acid.} \mathrm{The}$ suspension was then extracted with ethyl acetate $(2 \times 25 \mathrm{~mL})$, keeping the aqueous phase each time. After increasing $\mathrm{pH}$ of the aqueous phase to 10 with $25 \%$ ammonia solution, alkaloids were extracted with three equal volumes of ethyl acetate. The organic phase was washed with brine, dried over anhydrous sodium sulphate and evaporated to dryness to give $0.02 \mathrm{~g} ; 0.8 \%$ (conventional cultivation) and $0.03 \mathrm{~g} ; 1.2 \%$ (in vitro propagation), brownish-yellow alkaloid mixture, respectively.

The alkaloid mixtures obtained were dissolved in dichloromethane $(1.5 \mathrm{~mL})$ and subjected to GC/MS analysis. 
102

Gas Chromatography-Mass Spectrometry (GC-MS) analysis of the alkaloid mixture

The qualitative GC-MS analysis of the obtained alkaloid mixture was carried out using an HP 6890 gas chromatograph, equipped with a HP-5MS capillary column $(30 \mathrm{~m} \times 0.25 \mathrm{~mm}$; film thickness $0.25 \mu \mathrm{m}$ ) and coupled with HP 5973 Mass Selective Detector.

The flow rate of carrier gas $(\mathrm{He})$ was $1 \mathrm{~mL}^{-1}$. Samples of $4 \mu \mathrm{L}$ were injected in the split mode at a ratio of 5:1. The injector and the transfer line were kept at $280{ }^{\circ} \mathrm{C}$. The ion source temperature was $230^{\circ} \mathrm{C}$.

The initial temperature of the column was $40^{\circ} \mathrm{C}$ for $5 \mathrm{~min}$, then increased to $60^{\circ} \mathrm{C}$ at a rate of $30^{\circ} \mathrm{C} \mathrm{min}^{-1}$, next to $230^{\circ} \mathrm{C}$ at a rate of $6^{\circ} \mathrm{C} \mathrm{min}^{-1}$ (kept constant for $10 \mathrm{~min}$ ), and then increased to a final temperature of $280{ }^{\circ} \mathrm{C}$ at a rate of $30^{\circ} \mathrm{C}$ $\mathrm{min}^{-1}$. The oven was held at this temperature for $30 \mathrm{~min}$. Mass spectra were taken at $70 \mathrm{eV}$. Mass range was from 40 to $550 \mathrm{~m} / \mathrm{z}$. Solvent delay was $6 \mathrm{~min}$. The total running time for a sample was about 76 min.

The identification of the alkaloids was confirmed by comparing the mass spectral data with those of authentic compounds and with data obtained from the literature (Djerassi et al., 1962; Gilbert, 1965; Kohl et al., 1981; Zocoler et al., 2005; Zhao et al., 2013; Akhgari et al., 2015).

Further identification was made by comparison of their mass spectra with those stored in Wiley NBS75K, NIST 2005 and NIST 2008 mass spectral libraries (isovindolinine, vindolinine, ajmalicine, tetrahydroalstonine, pleiocarpamine).

Retention indices (RI) values were measured on HP-5MS column for all identified alkaloids. For RI calculation, a mixture of $n$-alkanes $\left(\mathrm{C}_{7}-\mathrm{C}_{40}\right)$ was used, under the same chromatographic conditions which were used for the analysis of ethanolic extracts.

The relative percentage of each component was evaluated from the total peak area (TIC) by the apparatus software.

\section{Statistical analysis}

The results of the study were subjected to an analysis of variance which was performed with AWAR software, made by Department of Applied Informatics, Institute of Soil Science and Plant Cultivation in Pulawy, Poland. The three experimental factors (I - alkaloid, II - propagation method, III - extraction method) were tested in a split-split-plot design and the means were separated using the Tukey's Studentized Range Test at $P=$ 0.05 .

\section{Results and Discussion}

In the current research the bioactive compounds of $C$. roseus extracts were analyzed by gas chromatography-mass spectrometry (GC-MS). A total of 15 different alkaloids have been identified (Table 1), among which vindoline (28.695-34.255\%), vindorosine (10.665-18.890\%) and ajmalicine (6.785-12.660\%) were the most abundant. Some alkaloids remained unidentified due to the lack of reference substances as well as the lack of mass spectra libraries. According to Hisiger and Jolicoeur (2007), about eight indole alkaloids are commercially available and only few (about 11) of the large group of these valuable compounds produced by periwinkle are frequently analyzed. Moreover, GC is unsuitable to the analysis of bisindole alkaloids as they have high melting point (Chen et al., 2013).
GC-MS chromatograms of ethanol extracts of $C$. roseus are presented in Fig. 1 and Fig. 2, while Fig. 3 shows the chemical structures of identified alkaloids.

Vindoline (30.865\%) was the main alkaloid of periwinkle herb (Table 1). Vindorosine (14.746\%) was the second one. High concentrations were also noted for ajmalicine (9.866\%), isovindolinine (9.239\%), vindolinine (8.209\%) and tetrahydroalstonine $(7.504 \%)$. The amounts of the other alkaloids ranged between 2.206 and $0.218 \%$.

There was also a significant interaction recorded between alkaloid and propagation method. Significant differences were noted in case of the four of alkaloids. Higher amounts of vindorosine and vindoline were detected according to the in vitro plant propagation, while for tetrahydroalstonine and ajmalicine conventional method of propagation. Moreover, an interaction between alkaloid and extraction method was also statistically significant for some of the compounds. In the case of isovindolinine, vindolinine and ajmalicine, extraction at $55^{\circ} \mathrm{C}$ was more effective, while for pericyclivine - maceration at room temperature. When using extraction at $55^{\circ} \mathrm{C}$ pericyclivine was not detected.

Mass spectrometry of $C$. roseus extracts indicated that isovindolinine, vindolinine, 19-epivindolinine, 20-epivindolinine and tabersonine have the same molecular ion at $\mathrm{m} / \mathrm{z} 336$ (Table 2).

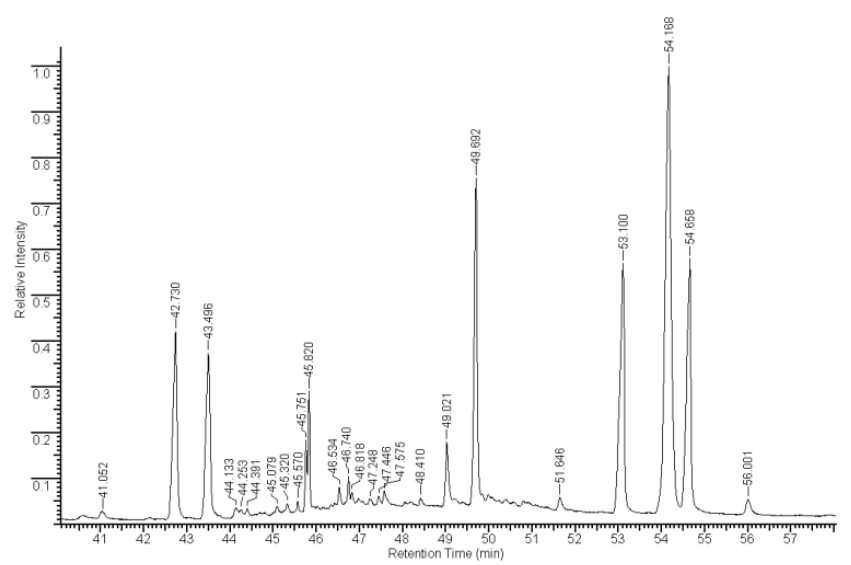

Fig. 1. GC-MS chromatogram obtained from alkaloids isolated from Catharanthus roseus L. (G.) Don by maceration at room temperature

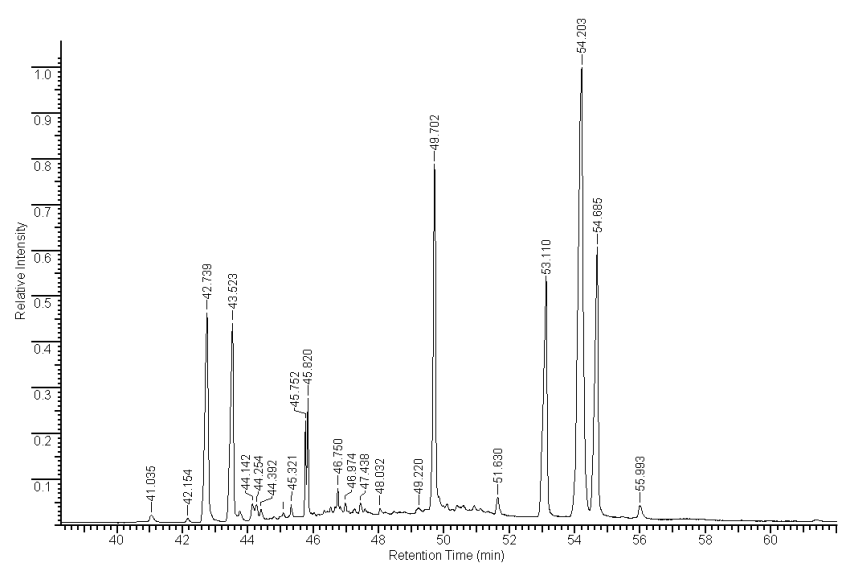

Fig. 2. GC-MS chromatogram obtained from alkaloids isolated from Catharanthus roseus L. (G.) Don by extraction at $55^{\circ} \mathrm{C}$ 
Table 1. Alkaloids identified by GC/MS in ethanolic extracts of Catharanthus roseus (L.) G. Don. The data are given as the mean \pm SD ( $\mathrm{n}=3$ )

\begin{tabular}{|c|c|c|c|c|c|c|c|c|c|c|}
\hline \multirow{2}{*}{ No. } & \multirow{2}{*}{ Name of alkaloid } & \multirow{2}{*}{$\begin{array}{c}\mathrm{R}_{\mathrm{t}} \\
{[\mathrm{min}]}\end{array}$} & \multirow{2}{*}{ RI } & \multicolumn{3}{|c|}{ Conventional propagation (area, \%) } & \multicolumn{3}{|c|}{ In vitro propagation (area, $\%)$} & \multirow{2}{*}{ Mean } \\
\hline & & & & I & II & Mean & I & II & Mean & \\
\hline 1. & Isovindolinine & 42.73 & 2559 & $7.670 \pm 0.16$ & $10.585 \pm 0.77$ & 9.128 & $7.325 \pm 3.66$ & $11.375 \pm 0.52$ & 9.350 & 9.239 \\
\hline 2. & Vindolinine & 43.50 & 2581 & $7.255 \pm 0.28$ & $9.200 \pm 0.66$ & 8.227 & $6.480 \pm 3.70$ & $9.900 \pm 0.55$ & 8.190 & 8.209 \\
\hline 3. & 19-Epivindolinine & 44.13 & 2600 & $0.650 \pm 0.28$ & $0.695 \pm 0.06$ & 0.673 & $0.570 \pm 0.16$ & $0.595 \pm 0.10$ & 0.582 & 0.627 \\
\hline 4. & 20-Epivindolinine & 44.25 & 2606 & $0.590 \pm 0.32$ & $0.625 \pm 0.08$ & 0.608 & $0.565 \pm 0.21$ & $0.535 \pm 0.10$ & 0.550 & 0.579 \\
\hline 5. & Tabersonine & 44.39 & 2615 & $0.270 \pm 0.01$ & $0.385 \pm 0.02$ & 0.327 & $0.115 \pm 0.08$ & $0.305 \pm 0.02$ & 0.210 & 0.269 \\
\hline 6. & Vincoline & 45.08 & 2657 & $0.320 \pm 0.03$ & $0.285 \pm 0.01$ & 0.303 & $0.095 \pm 0.09$ & $0.170 \pm 0.00$ & 0.133 & 0.218 \\
\hline 7. & Pleiocarpamine & 45.75 & 2698 & $1.120 \pm 0.04$ & $1.525 \pm 0.02$ & 1.322 & $0.980 \pm 0.22$ & $1.450 \pm 0.05$ & 1.215 & 1.269 \\
\hline 8. & Coronaridine & 45.82 & 2704 & $2.240 \pm 0.03$ & $2.120 \pm 0.07$ & 2.180 & $2.405 \pm 0.35$ & $2.060 \pm 0.09$ & 2.233 & 2.206 \\
\hline 9. & 16-Epivindolinine- $\mathrm{N}_{\mathrm{b}}$-oxide & 46.74 & 2784 & $0.885 \pm 0.09$ & $0.700 \pm 0.04$ & 0.793 & $1.375 \pm 0.86$ & $0.490 \pm 0.10$ & 0.933 & 0.863 \\
\hline 10. & Vindolidine & 47.58 & 2852 & $0.565 \pm 0.12$ & $0.175 \pm 0.01$ & 0.370 & $0.655 \pm 0.50$ & $0.295 \pm 0.05$ & 0.475 & 0.423 \\
\hline 11. & Pericyclivine & 49.02 & 2960 & $2.545 \pm 0.49$ & $-*$ & 1.273 & $3.285 \pm 0.95$ & - & 1.642 & 1.457 \\
\hline 12. & Vindorosine & 49.70 & 3007 & $10.665 \pm 0.39$ & $11.640 \pm 0.12$ & 11.153 & $17.790 \pm 3.18$ & $18.890 \pm 0.05$ & 18.340 & 14.746 \\
\hline 13. & Tetrahydroalstonine & 53.10 & 3193 & $11.430 \pm 0.23$ & $11.660 \pm 0.18$ & 11.545 & $3.175 \pm 0.05$ & $3.750 \pm 0.00$ & 3.463 & 7.504 \\
\hline 14. & Vindoline & 54.17 & 3238 & $28.695 \pm 1.19$ & $29.225 \pm 1.13$ & 28.960 & $34.255 \pm 5.45$ & $31.285 \pm 1.19$ & 32.770 & 30.865 \\
\hline 15. & Ajmalicine & 54.66 & 3259 & $10.865 \pm 0.68$ & $12.660 \pm 0.08$ & 11.762 & $6.785 \pm 0.57$ & $9.155 \pm 0.38$ & 7.970 & 9.866 \\
\hline Mean & & & & 5.718 & 6.099 & 5.908 & 5.724 & 6.017 & 5.870 & 5.889 \\
\hline \multicolumn{2}{|c|}{$\mathrm{LSD}_{\alpha=0.05}$ for alkaloid (I) } & & & & & 4.698 & & & & \\
\hline \multicolumn{2}{|c|}{$\mathrm{LSD}_{\alpha=0.05}$ for propagation method(II) } & & & & & $n . s$. & & & & \\
\hline \multicolumn{2}{|c|}{$\mathrm{LSD}_{\alpha=0.05}$ for extraction method(III) } & & & & & n.s. & & & & \\
\hline \multicolumn{11}{|c|}{$\mathrm{LSD}_{\alpha=0.05}$ for interaction: } \\
\hline \multicolumn{2}{|l|}{$\mathrm{I} \times \mathrm{II}$} & & & & & 1.920 & & & & \\
\hline \multicolumn{2}{|l|}{ IXIII } & & & & & 1.901 & & & & \\
\hline \multicolumn{2}{|l|}{ II $\times$ III } & & & & & n.s. & & & & \\
\hline
\end{tabular}

RI: retention indices relative to n-alkanes $\left(\mathrm{C}_{7}-\mathrm{C}_{40}\right)$ on $\mathrm{HP}-5 \mathrm{MS}$ column

$\mathrm{I}$ : maceration at room temperature; II : extraction at $55^{\circ} \mathrm{C}$

* - not detected

n.s. - not significant

Table 2. Mass spectra data of alkaloids identified in ethanolic extracts of Catharanthus roseus L. cultivated conventionally and derived from in vitro cultures

\begin{tabular}{|c|c|c|c|}
\hline Alkaloid & Molecular formula & {$\left[\mathrm{M}^{+}\right](\%)$} & $m / z$ (relative intensity), $\%$ \\
\hline Isovindolinine & $\mathrm{C}_{21} \mathrm{H}_{24} \mathrm{~N}_{2} \mathrm{O}_{2}$ & $336(100)$ & $\begin{array}{l}321\left[\mathrm{M}^{+}-\mathrm{CH}_{3}\right](3), 305\left[\mathrm{M}^{+}-\mathrm{OCH}_{3}\right](8), 277\left[\mathrm{M}^{+}-\mathrm{CO}_{2} \mathrm{CH}_{3}\right](5), 230(35), 216(30), 202(17), 183(13), 170(87), 156 \\
(36), 135(79), 134(88), 120(29), 108(14), 91(15)\end{array}$ \\
\hline Vindolinine & $\mathrm{C}_{21} \mathrm{H}_{24} \mathrm{~N}_{2} \mathrm{O}_{2}$ & $336(100)$ & $\begin{array}{l}321(3), 305(9), 277(5), 230(33), 216(30), 202(16), 183(12), 170(83), 156(33), 135(77), 134(85), 120(27), 115 \\
(14), 107(21), 93(16)\end{array}$ \\
\hline 19-Epivindolinine & $\mathrm{C}_{21} \mathrm{H}_{24} \mathrm{~N}_{2} \mathrm{O}_{2}$ & $336(100)$ & $\begin{array}{l}321(6), 305(8), 277(8), 229(21), 202(12), 194(25), 180(19), 170 \text { (40), } 156(20), 134(51), 122(44), 107(10), 91 \\
(11), 77(14)\end{array}$ \\
\hline 20-Epivindolinine & $\mathrm{C}_{21} \mathrm{H}_{24} \mathrm{~N}_{2} \mathrm{O}_{2}$ & $336(100)$ & $\begin{array}{l}321(6), 305(7), 277(14), 229(24), 202(13), 194(24), 180(19), 170(47), 156(26), 134(63), 122(48), 107(10), 91 \\
(14), 77(16)\end{array}$ \\
\hline Tabersonine & $\mathrm{C}_{21} \mathrm{H}_{24} \mathrm{~N}_{2} \mathrm{O}_{2}$ & $336(100)$ & $\begin{array}{l}305(9), 277(7), 229(22), 216(33), 202(6), 194(15), 180(14), 168(25), 156(26), 135(54), 122(31), 107(33), 92(5) \text {, } \\
93(9), 77(12)\end{array}$ \\
\hline Vincoline & $\mathrm{C}_{21} \mathrm{H}_{24} \mathrm{~N}_{2} \mathrm{O}_{4}$ & $368(2)$ & $\begin{array}{l}356(7), 336(100), 319(6), 304(16), 278(12), 230(18), 216(21), 183(22), 170(62), 156(36), 135(50), 134(64), 122 \\
(22), 120(24), 107(25), 93(13)\end{array}$ \\
\hline Pleiocarpamine & $\mathrm{C}_{20} \mathrm{H}_{22} \mathrm{~N}_{2} \mathrm{O}_{2}$ & $322(96)$ & $\begin{array}{l}307(8), 293(4), 292(4), 263\left[\mathrm{M}^{+}-\mathrm{CO}_{2} \mathrm{CH}_{3}\right](100), 247(12), 232(34), 218(19), 194(14), 180(83), 167(15), 131 \\
(15), 121(5), 108(14)\end{array}$ \\
\hline Coronaridine & $\mathrm{C}_{21} \mathrm{H}_{26} \mathrm{~N}_{2} \mathrm{O}_{2}$ & $338(100)$ & $323(30), 309(6), 253(11), 214(25), 136(75), 135(22), 124(34), 122(29), 108(10), 96(8), 77(6), 41(11)$ \\
\hline 16-Epivindolinine- $\mathrm{N}_{\mathrm{b}}$-oxide & $\mathrm{C}_{21} \mathrm{H}_{24} \mathrm{~N}_{2} \mathrm{O}_{3}$ & $352(3)$ & $\begin{array}{l}351(7), 338(2), 335(23), 334(100), 321(1), 319(3), 305(3), 293(21), 281(14), 275(11), 249(22), 227(58), 207 \\
(31), 194(60), 182(23), 167(90), 149(74), 127(19), 108(71), 92(14)\end{array}$ \\
\hline Vindolidine & $\mathrm{C}_{24} \mathrm{H}_{30} \mathrm{~N}_{2} \mathrm{O}_{5}$ & $426(7)$ & $\begin{array}{l}367(20), 282(7), 281(20), 267(75), 266(5), 207(40), 158(100), 144(21), 143(27), 135(14), 107(15), 93(7), 92 \\
(11), 77915)\end{array}$ \\
\hline Pericyclivine & $\mathrm{C}_{20} \mathrm{H}_{2} \mathrm{~N}_{2} \mathrm{O}_{2}$ & $322(100)$ & $\begin{array}{l}321(82), 307(29), 291\left[\mathrm{M}^{+}-\mathrm{OCH}_{3}\right](8), 263\left[\mathrm{M}^{+}-\mathrm{CO}_{2} \mathrm{CH}_{3}\right](31), 249(19), 235(11), 207(10), 181(12), 180(7), 169 \\
(69), 168(67), 154(13)\end{array}$ \\
\hline Vindorosine & $\mathrm{C}_{24} \mathrm{H}_{30} \mathrm{~N}_{2} \mathrm{O}_{5}$ & $426(6)$ & $366(7), 282(13), 279(16), 267(13), 266(26), 207(2), 158(94), 135(100), 121(26), 107(18), 93(9), 77(6)$ \\
\hline Tetrahydroalstonine & $\mathrm{C}_{21} \mathrm{H}_{24} \mathrm{~N}_{2} \mathrm{O}_{3}$ & $352(100)$ & $\begin{array}{l}337(33), 293\left[\mathrm{M}^{+}-\mathrm{CO}_{2} \mathrm{CH}_{3}\right](6), 251(13), 223(19), 197(9), 184(9), 170(10), 169(19), 156(39), 129(9), 115(6), 77 \\
(4), 55(5)\end{array}$ \\
\hline Vindoline & $\mathrm{C}_{25} \mathrm{H}_{32} \mathrm{~N}_{2} \mathrm{O}_{6}$ & $456(15)$ & $\begin{array}{l}397\left[\mathrm{M}^{+}-\mathrm{CO}_{2} \mathrm{CH}_{3}\right](9), 309(13), 296(25), 282(29), 188(84), 174(37), 161 \text { (22), } 135(100), 121(42), 107(20), 93 \\
(12)\end{array}$ \\
\hline Ajmalicine & $\mathrm{C}_{21} \mathrm{H}_{24} \mathrm{~N}_{2} \mathrm{O}_{3}$ & $352(100)$ & $\begin{array}{l}337(6), 321\left[\mathrm{M}^{+}-\mathrm{OCH}_{3}\right](5), 293\left[\mathrm{M}^{+}-\mathrm{CO}_{2} \mathrm{CH}_{3}\right](2), 265(5), 225(7), 209(13), 184(34), 170(8), 169(19), 156(51), \\
143(7), 129(7), 115(5), 77(4)\end{array}$ \\
\hline
\end{tabular}

Moreover, 19-epivindolinine, 20-epivindolinine and tabersonine showed similar fragmentation patterns and retention times (Table $1)$, very close to each other.

Dejerassi et al. (1962) reported that peaks at $\mathrm{m} / \mathrm{z} 93,107,120$, 121,122 as well as at $\mathrm{m} / \mathrm{z} 134,135$ are associated with the piperidine portion of the molecule and occurs in all mass spectra of the vindolinine series. This group is dominated by vindolinine, 19epivindolinine and their $\mathrm{N}_{b}$-oxides.
Vindolinine and tabersonine with $\left[\mathrm{M}^{+}\right]$at $336 \mathrm{~m} / \mathrm{z}$ are considered as catharanthine isomers (Ferreres et al., 2010).

Interestingly, the base peak at $\mathrm{m} / \mathrm{z} 336(100 \%)$ in vincoline corresponds to the molecular ion of vindolinine $\left(\mathrm{M}^{+}, 336\right)$. The presence of peaks at $\mathrm{m} / \mathrm{z} 93,107,120,122$ and 135 shows that the both compounds belong to the same group. Svoboda et al. (1964) noted similarities in the case of IR and NMR spectra of these compounds. 
104

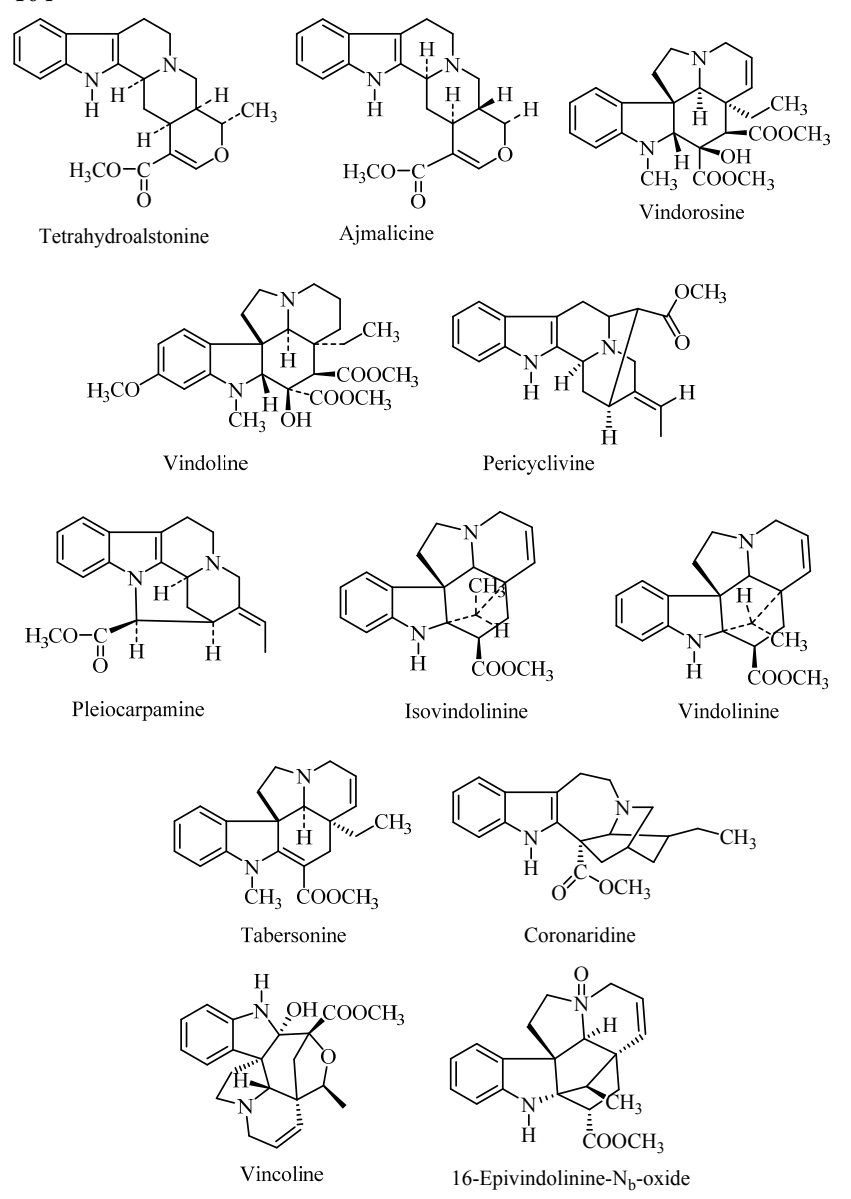

Fig. 3. Chemical structures of identified alkaloids

Pleiocarpamine shows prominent signals at $\mathrm{m} / \mathrm{z} 322\left(\mathrm{M}^{+}\right)$, $\mathrm{m} / \mathrm{z} 263\left(\mathrm{M}^{+}-\mathrm{CO}_{2} \mathrm{CH}_{3}\right)$ and $\mathrm{m} / \mathrm{z} 180$ (quinolium ion). Our results are in agreement with published data for pleiocarpamine (Hesse et al., 1964; Akhgari et al., 2015).

Comparing the mass spectrum of coronaridine with literature data (Zocoler et al., 2005), we were observing only small differences in the relative ion intensities.

The mass spectrum of pericyclivine was characterized by the ions at $\mathrm{m} / \mathrm{z}$ 322, 321, 291, 263 and 169. Similar fragmentation patterns was noted by Vieira et al. (2008).

The spectra of ajmalicine and tetrahydroalstonine exhibited fragments of the $\beta$-carboline skeleton at $\mathrm{m} / \mathrm{z} 184,170,169$ and 156 , which is in accordance with the results published by Hesse (1974). However, both compounds were identified according to standards.

Vindorosine (molecular weight, 426) showed difference of 30 $\mathrm{m} / \mathrm{z}$ in mass as compared to vindoline (molecular weight, 456). This may suggest that vindorosine is derivative of vindoline. Moreover, vindolidine and vindorosine have the same molecular ion at $\mathrm{m} / \mathrm{z}$ 426. Slight differences were noted only in their intensity. Detailed fragmentation patterns of the mass spectra of these compounds can be found in Table 2. The major peaks observed in the mass spectrum of vindorosine were the same as those reported by Zhao et al. (2013).

Our results indicated that the GC-MS method can be successfully applied for the analysis of the mixture of periwinkle alkaloids without necessity of derivatization. Kreh et al. (1995), who applied for the first time GC-MS in the analysis of underivatized Amaryllidaceae alkaloids from Narcissus pseudonarcissus have demonstrated its advantages over the analysis of silylated samples. Tram et al. (2002) reported the results of GCMS analysis of underivatized alkaloids from leaves of Crinum latifolium, while Tosun and Tamer (2004) used this method for determination of pyrrolizidine alkaloids in seeds of Heliotropium europaeum.

According to Subbaiyan et al. (2014), gas chromatography coupled to mass spectrometry is the best for identification of long chain hydrocarbons, alcohols, acids, esters, alkaloids, steroids and nitrogen compounds.

Catharanthus roseus is one of the main source of terpenoid indole alkaloids used for the preparation of diabetic drugs, cardiac drugs, in hypertension and in anticancer drugs formation by the pharmaceutical industries (Misra et al., 2009). Moreover, some of these therapeutic molecules are obtained by semi-synthesis using natural precursors extracted from $C$. roseus leaves.

The low content of dimeric alkaloids in the plant as well as their high market price encouraged the researchers to improve the production of these valuable metabolites through the technique of tissue cultures. The influence of concentration of different growth regulators on the production of callus and the amount of synthesized alkaloids have been investigated (Misawa, 1994; Junaid et al., 2008; Kalidass et al., 2010; Verma et al., 2012; Soleimani et al., 2013).

Soleimani et al. (2013) reported stimulatory effect of 2,4-D (2,4-dichlorophenoxyacetic acid) on callus formation as well as on the level of vinblastine and vincristine. They also found that increasing the concentration of kinetin resulted in a significant decrease in callogenesis and alkaloid production. Kalidass et al. (2010) demonstrated that the use of kinetin in a concentration above $1 \mathrm{mg} \cdot \mathrm{dm}^{-3}$ had less effect of vinblastine production. Moreover, increase of its concentration was associated with decrease of vinblastine synthesis.

Verma et al. (2012) revealed that half strength basal MS medium supplemented with 2,4-D and BAP $\left(0.5 \mathrm{mg} \cdot \mathrm{dm}^{-3}\right.$ and 1.0 $\mathrm{mg} \cdot \mathrm{dm}^{-3}$, respectively), and with $6 \%$ sucrose was the best for callus biomass production along with high alkaloid content.

Generally, the auxins were approved as the best for callus proliferations and growth. However, the combination of auxins with cytokinins were found to be better for leaf callus growth and enhancement in alkaloids content (Misawa, 1994; Junaid et al., 2008).

An antagonistic effect of gibberellins and cytokinins on the biosynthesis of monoterpenoid indole alkaloids in $C$. roseus was reported by Amini et al. (2009). According to them, the inhibitory effect of gibberellin was correlated with the silencing of two genes, encoding enzymes of the alkaloids biosynthetic pathway. Normally this process is regulated by cytokinins. In case of exogenously applied cytokinin they observed considerably increase of synthesis of ajmalicine and serpentine in untransformed cotyledon callus. The use of 2,4-D decreased the accumulation of these metabolites.

Garnier et al. (1996) found that BAP (6-benzylaminopurine) and in some cases NAA (naphtahleneacetic acid) stimulated the accumulation of vindoline and catharanthine in periwinkle.

In general, MS medium is most widely used in tissue cultures, but the number of inorganic and organic salts and their levels are usually different. The ammonium and nitrate ions inhibit alkaloids production (Van Gulik et al., 1993). These salts are added to the media for growth promotion and differentiation.

The maximum production of alkaloids occurs at low levels of phosphate, nitrate and ammonia in the medium (Schlatmann et 
al., 1992).

Vitamins and organic components had slight effect on the alkaloids production. Only in case of glucose positive effect on ajmalicine production in hairy-root culture was noted by Moreno et al. (1995). On the other hand, Zhao et al. (2001) showed that the addition of succinic acid, tryptamine and tryptophan to the culture medium caused significant growth of ajmalicine and catharanthine levels.

The present study indicated that the MS basal medium supplemented with kinetin $\left(2.0 \mathrm{mg} \cdot \mathrm{dm}^{-3}\right)$, IBA $\left(1.0 \mathrm{mg} \cdot \mathrm{dm}^{-3}\right)$, NAA $\left(0.2 \mathrm{mg}_{\mathrm{dm}}{ }^{-3}\right)$ and sucrose $\left(30 \mathrm{mg} \cdot \mathrm{dm}^{-3}\right)$ caused the increase of the production of vindorosine and vindoline in $C$. roseus tissue cultures. However, increasing the levels of important periwinkle alkaloids is extremely difficult and dependent on many factors. This explains why the role of different plant growth regulators in regulating monoterpene indole alkaloids (MIAs) biosynthetic pathway is still being extensively investigated.

\section{Conclusion}

The obtained results showed that the plants cultivated conventionally had higher amounts of ajmalicine and tetrahydroalstonine, while these from in vitro propagation higher amounts of vindorosine and vindoline. Moreover, the temperature of extraction also affected the percentage content of isolated alkaloids. In case of isovindolinine, vindolinine and ajmalicine the more effective was extraction at $55^{\circ} \mathrm{C}$, while for pericyclivine - maceration at room temperature. Our study may find wide applications in the optimization of production and isolation of $V$ inca alkaloids.

\section{References}

Amini A, Glevarec G, Andreu R, Rideau M, Creche J (2009). Low levels of gibberellic acid control the biosynthesis of ajmalicine in Catharanthus roseus cell suspension cultures. Planta Medica 75(2):187-191.

Aslam J, Khan SH, Siddiqui ZH, Zohra F, Maqsood M, Bhat MA, Nasim SA, Illah A, Ahmad IZ, Khan SA, Mujib A, Sharma MP (2010). Catharanthus roseus (L.) G. Don. An important drug: it's applications and production. International Journal of Comprehensive Pharmacy $1(4): 1-16$

Almagro L, Fernandez-Perez F, Pedreño MA (2015). Indole alkaloids from Catharanthus roseus: bioproduction and their effect on human health. Molecules 20:2973-3000.

Akhgari A, Laakso I, Seppänen-Laakso T, Yrjönen T, Vuorela H, OksmanCaldentey K-M, Rischer H (2015). Determination of terpenoid indole alkaloids in hairy roots of Rhazya stricta (Apocynaceae) by GC-MS Phytochemical Analysis 26:331-338.

Carev DP, Patterson BD (1970). The effect of antibiotics on the growth of Catharanthus roseus tissue cultures. Lloydia 33:275-277.

Chen Q, Zhang W, Zhang Y, Chen J, Chen Z (2013). Identification and quantification of active alkaloids in Catharanthus roseus by liquid chromatography-ion trap mass spectrometry. Food Chemistry $139: 845-852$

Djerassi C, Flores SE, Budzikiewicz H, Wilson JM, Durham LJ, Le Men J, Janot M-M, Plat M, Gorman M, Neuss N (1962). Mass spectrometry in structural and stereochemical problems, IV. Vindolinine. Proceedings of the National Academy of Sciences 48(2):113-120.
El-Sayed A, Cordell GA (1981). Catharanthus alkaloids, catharanthamine, a new antitumor bisindole alkaloid from Catharanthus roseus. Journal of Natural Products 44(3):289-293.

Ferreres F, Pereira DM, Valentao P, Oliveira JMA, Faria J, Gaspar L, Sottomayor M, Andrade PB (2010). Simple and reproductible HPLCDAD-ESI-MS/MS analysis of alkaloids in Catharanthus roseus roots. Journal of Pharmaceutical and Biomedical Analysis 51(1):65-69.

Gajalakshmi S, Vijayalakshmi S, Rajeswari DV (2013). Pharmacological activities of Catharanthus roseus: a perspective review. International Journal of Pharma and Bio Sciences 4(2):431-439.

Garg G (2010). In vitro screening of Catharanthus roseus L. cultivars for salt tolerance using physiological parameters. International Journal of Environmental Science and Development 1(1):2430.

Garnier F, Carpin S, Label P, CrecheJ, Rideau M, HamdiS (1996). Effect of cytokinin on alkaloid accumulation in periwinkle callus cultures transformed with a light-inducible ipt gene. Plant Science 120(1):47-55.

Gilbert B (1965). The alkaloids of Aspidosperma, Diplorrhyncus, Kopsia, Ochrosia, Pleiocarpa and related Genera. In: Manske RHF (Ed). The Alkaloids Chemistry and Physiology Vol. VIII. Academic Press Inc. New York, USA.

Hesse M, Phillipsborn W, Schumann D, Spiteller G, Spiteller-Friedman M, Taylor WI, Schmid H, Karrer P (1964). Die Strukturen von CFluorocurin. C-Mavacurin and Pleiocarpamin. 57 Mitt. Über CurareAlkaloide. Helvetica Chimica Acta 47(3):878-911.

Hesse M (1974). Indolalkaloide. In: Budzikiewicz H (Ed). Fortschritte der Massenspectrometrie. Vol. 1, VerlagChemie, Weinheim.

Hisiger S, Jolicoeur M (2007). Analysis of Catharanthus roseus alkaloids by HPLC. Phytochemistry Reviews 6(2):207-234.

Joy PP, Thomas J, Mathew S, Skaria BP (1998). Medicinal Plants. Kerala, India: Kerala Agricultural University, Aromatic and Medicinal Plants Research Station pp 42-43.

Junaid A, Mujib A, FatimaS, Sharma MP (2008). Cultural conditions affect somatic embryogenesis in Catharanthus roseus L. (G.) Don. Plant Biotechnology Reports 2:179-189.

Kalidass Ch, Mohan VR, Daniel A (2010). Effect of auxin and cytokinins on vincristine production by callus cultures of Catharanthus roseus $\mathrm{L}$. (Apocynaceae). Tropical and Subtropical Agroecosystems 12:283-288.

Khode PP, Ghatol PU, Bhuyar SA, Deo DD, Dhumal VM (2000). Performance of Vinca rosea (Catharanthus spp.) to different fertility and irrigation levels. Agricultural Science Digest 20(2):135-136.

Kohl W, Witte B, Höfle G (1981). Alkaloids from Catharanthus roseus tissue cultures, II [1].Zeitschrift für Naturforschung 86b:1153-1162.

Kreh M, Matusch R, Witte L (1995). Capillary gas chromatography-mass spectrometry of Amaryllidaceae alkaloids. Phytochemistry 38(3):773776.

Kulkarni RN, Baskaran K, Chandrashekara RS, Kumar S (1999). Inheritance of morphological traits of periwinkle mutants with modified contents and yields of leaf and root alkaloids. Plant Breeding 118(1):7174.

Kumari K, Gupta S (2013). Phytopotential of Catharanthus roseus L. (G.) Don var. 'Rosea' and 'Alba' against various pathogenic microbes in vitro. International Journal of Research in Pure and Applied Microbiology 3(3):77-82. 
106

Laflamme P, St-Pierre B, De Luca V (2001). Molecular and biochemical analysis of a Madagascar periwinkle root-specific minovincinine-19hydroxy-O-acetyltransferase. Plant Physiology 125(1):189-198.

Larbie Ch, Abboah-Offei O (2014). Anticancer properties of some ornamental plants on Knust Kampus, Kumasi, Ghana. International Journal of Phytopharmacology 5(5):366-370.

Marles R, Farnsworth (1995). Antidiabetic plants and their active constituents. Phytomedicine2(2):137-189.

Miranda-Ham M de L, Islas-Flores I, Vazquez-Flota F (2007). Accumulation of monoterpenoid indole alkaloids in periwinkle seedlings (Catharanthus roseus) as a model for the study of plantenvironment interactions. Biochemistry and Molecular Biology Education 35(3):206-210.

Misawa M (1994). Plant Tissue Culture: an alternative for production of useful metabolites (FAO Agricultural Services Bulletin), Bio International Inc, Toronto, Canada, p. 17-19.

Mishra P, Uniyal GC, Sharma S, Kumar S (2001). Pattern of diversity for morphological and alkaloid yield related trades among the periwinkle Catharanthus roseus accessions collected from in and around Indian Subcontinent. Genetic Resources and CropEvolution 48(3):273-286.

Misra A, Srivastava NK, Srivastava AK, Khan A (2009). Influence of ethereal and gibberellic acid on carbon metabolism, growth, and alkaloids accumulation in Catharanthus roseus L. African Journal of Pharmacy and Pharmacology 3(11):515-520.

Moreno PRH, Van der Heijden R, Verpoorte R (1995). Cell and tissue cultures of Catharanthus roseus; a literature survey II. Updating from 1988-1993. Plant Cell, Tissue and Organ Culture 42:1-25.

Murashige T, Skoog S (1962). A revised medium for rapid growth and bioassays with tobacco cultures. Physiologia Plantarum 15:473-497.

Noble RL (1990). The discovery of the vinca alkaloids-chemotherapeutic agents against cancer. Biochemistry and Cell Biology 68(12):13441351.

Ramirez J, Ogan K, Ratain MJ (1997). Determination of vinca alkaloids in human plasma by liquid chromatography/atmospheric pressure chemical ionization mass spectrometry. Cancer Chemotherapy and Pharmacology 39:286-290.

Schaltmann JE, Ten Hoopen HJG, Heijnen JJ (1992). Optimization of the medium composition for alkaloid production by Catharanthus roseus using statistical experimental designs. Mededelingen van de Faculteit Landbowwetenschappen-Rijksuniversiteit Gent 57:1567-1569.

Soleimani F, Zarghami R, Ebrahimzadeh M (2013). Effects of 2,4D and kinetin concentrations of vinblastine and vincristine alkaloid contents in callus of periwinkle (Catharanthus roseus). International Journal of AgriScience3(10):759-765.

Subbaiyan BP, Samydurai M, Prabu KM, Thangapandin V (2014). Gas chromatography and mass spectrum analysis of Catharanthus Pusillus Murray G. Don (Apocynaceae). International Research Journal of Pharmaceutical and Applied Sciences 4(2):48-52.
Svoboda GH, Gorman M, Tust RH (1964). Alkaloids of Vinca rosea (Catharanthus roseus), XXV. Lochrovine, permivine, vincoline, lochrovidine, lochrovicine and vincolidine. Lloydia 27:203-213.

Svoboda GA (1969). The alkaloids of Catharanthus roseus G. Don (Vinca rosea L.) in cancer chemotherapy. In: Gunkel JE (Ed.). Current topics in plant science. Academic Press, New York, USA, p. 303-335.

Tabakovic I, Gunic E, Juranic I (1997). Anodic fragmentation of catharanthine and coupling with vindoline. Formation of anhydrovinblastine. Journal of Organic Chemistry 62:947-953.

Thomas PA, Peninisin B, Stegelin F, Woodward J (2012). A guide for commercial production of $V$ inca. Biulletin 1219:1-27.

Tosun F, Tamer U (2004). Determination of Pyrrolizidine alkaloids in the seeds of Heliotropium Europaeum by GC-MS. Journal of Faculty of Pharmacy Ankara University 33(1):7-9.

Tram NTN, Mitova M, Bankova V, Handjieva N, Popov SS (2002). GCMS of Crinum latifolium L. Alkaloids. Zeitschrift für Naturforschung 57c:239-242.

Van Gulik WM, Ten Hoopen HJG, Heijnen JJ (1993). A structured model describing carbon and phosphate limited growth of Catharanthus roseus plant cell suspensions in batch and chemostat cultures. Biotechnology and Bioengineering 41(8):771-780.

Verma AK, Singh RR, Singh S (2012). Improved alkaloid content in callus culture of Catharanthus roseus. BotanicaSerbica36(2):123-130.

Vieira IJC, Medeiros WLB, Monnerat CS, Souza JJ, Mathias L, Braz-Filho R, Pinto AC, Sousa PM, Rezende CM, Epifanio R de A (2008). Two fast methods (GC-MS and TLC-ChEI assay) for rapid evaluation of potential anticholinestearasic indole alkaloids in complex mixture. Anais da Academia Brasileira de Ciencias (Annals of the Brazilian Academy of Sciences) 80(3):419-426.

Zhao J, Hu Q, Guo YQ, Zhu WH (2001). Effects of stress factors, bioregulators, and synthetic precursors on indole alkaloid production in compact callus clusters of Catharanthus roseus. Applied Microbiology and Biotechnology 55(6):693-698.

Zhao L, Sander GW, Shanks JV (2013). Perspectives of the metabolic engineering of terpenoid indole alkaloids in Catharanthus roseus hairy roots. Advances in Biochemical Engineering/Biotechnology 134:23-54.

Zocoler MA, de Oliveira AJB, Sarragiotto MH, Grzesiuk VL, Vidotti GJ (2005). Qualitative determination of indole alkaloids of Tabernaemontana fuchsiaefolia (Apocynaceae). Journal of the Brazilian Chemical Society 16(6B):1372-1377. 